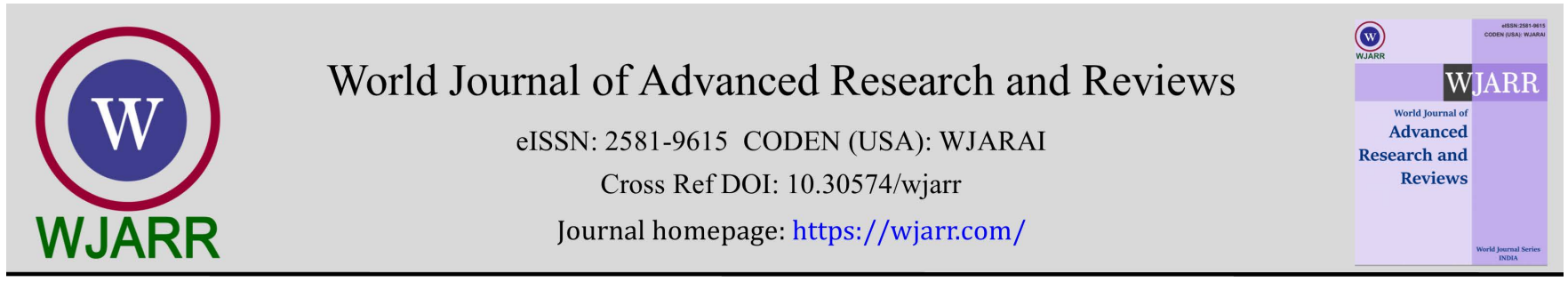

(RESEARCH ARTiClE)

Check for updates

\title{
Bacterial cellulose membrane enriched with fibroblast growth factor associated with photobiomodulation: In vitro evaluation
}

Hananiah Tardivo Quintana 1, João Paulo dos Santos Prado 1, Alan de França 1, Paulo Roberto GabbaiArmelin ${ }^{1}$, Daniel Vitor de Souza ${ }^{1}$, Daniel Araki Ribeiro ${ }^{1}$, Nivaldo Antonio Parizotto ${ }^{2,3}$, Hernane da Silva Barud ${ }^{4,}{ }^{*}$ and Ana Claudia Muniz Renno ${ }^{1}$

${ }^{1}$ Department of Biosciences, Federal University of São Paulo, UNIFESP, SP, Brazil.

${ }^{2}$ Department of Physiotherapy, Federal University Paraíba, João Pessoa, PB, Brazil.

${ }^{3}$ Biomedical Engineering Program, University Brazil, São Paulo, SP, Brazil.

${ }^{4}$ University Center of Araraquara, UNIARA, Araraquara, SP, Brazil.

World Journal of Advanced Research and Reviews, 2021, 09(02), 076-089

Publication history: Received on 19 January 2021; revised on 11 February 2021; accepted on 13 February 2021

Article DOI: https://doi.org/10.30574/wjarr.2021.9.2.0043

\begin{abstract}
One promising skin substitutes in the wound healing are the bacterial cellulose membranes (BCM). These biomaterials present nanostructures composed of microfibrils capable of forming three-dimensional pores that allow cell. In association with these biopolymers, several treatments are used, such as enrichment by growth factors and/or the application of photobiomodulation (PBM). Therefore, the aim of this study was to investigate the viability, proliferation and cytotoxicity of a BCM (culturing of Komagataeibacter xylinus), with or without FGF-2 in association with PBM therapy. In the characterization of BCM we saw that the membrane does not show great variations in $\mathrm{pH}$ and with the scanning electron microscopy it was possible to observe that the BCM has a denser and a porous side that allows the adhesion of fibroblasts, confirmed by histological staining and DAPI/Phalloidin. In vitro evaluation showed that the immunofluorescence (CaAM/EthD-1) for live and dead cells presented, in the groups with combined treatment at longterm of PBM and FGF-2, a greater quantity of live cells than with these isolated treatments and/or at short-term. However, in the short-term of combined treatment PBM and FGF-2 supplementation, fibroblasts and macrophages were more viable by Alamar Blue, in direct and indirect contact respectively. The comet assay did not show cytotoxicity for DNA damage in fibroblasts indirect contact with membrane extract. The results highlight the potential of association of FGF-2 supplementation with the application of PBM for use with BCM, due to its promoted increased cell density at long-term and improved viability in fibroblasts and macrophages at short-term.
\end{abstract}

Keywords: Bacterial cellulose membrane; Biopolymers; Fibroblast growth factor; Photobiomodulation; Fibroblast; Macrophages.

\section{Introduction}

In the area of tissue engineering there are great efforts to improve the tissue regeneration process of skin injuries in terms of the development of biomaterials that serve as a substitute for injured skin [1]. Skin substitutes can be classified into epidermal, dermal and epidermal-dermal and trilayered, replacing the dermal layers according to their names.

The most commonly used types of substitutes are gels, creams, resins, oils, films, membranes, scaffolds and grafts [2,3]. These biomaterials can be made using several materials such as: collagen, fibrin, alginate, hyaluronic acid and bacterial cellulose [4].

\footnotetext{
* Corresponding author: Hernane da Silva Barud; Email: hernane.barud@gmail.com

University Center of Araraquara, UNIARA, Araraquara, SP, Brazil.
} 
Among these biomaterials used for regeneration of skin injuries, the bacterial cellulose is one of the natural polysaccharides that has been widely explored [5]. It is obtained directly from the culture of bacteria, such as the genre Komagataeibacter xylinus, and this polysaccharide can be conveniently kept in the form of a bacterial cellulose membrane (BCM) [6,7].

The BCM has a nanostructure composed of microfibrils capable of forming three-dimensional pores [6,7]. The BCM has a high biocompatibility, besides features like high water content, crystallinity, elasticity, permeability, and high purity which permit a wide range of applications as bio-curatives for treatments of skin injuries [5,7-9]. In previous studies with models in rats of deep skin injuries, researchers observed that groups treated with BCM showed improvement in tissue regeneration when compared to the control group without treatment $[1,10]$.

Even with all these good properties of the BCM, its performance on repairing skin injuries could be enhanced by the incorporation of a specific growth factor. During tissue repair of the skin, the fibroblast growth factor (FGF) has an important role in the stimulation of fibroblasts to form new collagen and other important extracellular matrix components [11]. In previous in vitro studies, the isoform of FGF-2 was able to stimulate various cellular functions, such as inducing potent proliferative responses, cell migration and extracellular matrix production [12,13]. Currently, various types of products enriched with exogenous growth factors are commercially available, as gel and lotion. Such products provide potential benefits for the treatment of chronic and extensive skin injuries, since in these sites the expression levels of endogenous growth factors are lower [14].

Another promising resource that complements the use of biomaterials incorporated with GF for skin injuries healing process is the photobiomodulation (PBM). PBM is a very well-known noninvasive approach to the therapy of several kind of injuries $[15,16]$. In this sense, PBM acts through the absorption of an electromagnetic irradiation in a specific molecule, known as a chromosphere, which is located on the mitochondrial crest of cells $[15,17,18]$.

The therapeutic effects of the PBM are to consecutively increase enzyme activity, electron transport, mitochondrial respiration and ATP production[19,20]. PBM also alters the cellular redox state that induces activation of numerous intracellular signaling pathways and increases the affinity of growth factors related to tissue proliferation, survival and regeneration [15]. Additionally, PBM modulates certain growth factors, such as FGF, increasing the expression of this factor $[11,21]$. In the skin, PBM stimulates proliferation, differentiation and migration of cells such as fibroblasts and keratinocytes present in the wound bed, providing the improvement of the healing process [19,22]. Thus, all of these PBM benefits lead to modulation of the inflammation, decrease in pain and promotion of tissue repair [19,20].

Following this line, Brassolatti and co-authors [1] verified that the combination of BCM with PBM therapy, toward the treatment of deep skin injuries on the back of rats, led to increased vascular endothelial growth factor (VEGF) immune expression and neovascularization compared to BCM and PBM groups [1]. These findings show that the combined treatments are very promising since they can stimulate the angiogenesis and modulate the inflammatory process, decreasing the healing time and enhancing the quality of skin repair.

Taken together, all these information show that BCM have appealing properties to be a temporary skin replacement and may properly interact with other therapy approaches, such as the incorporation of GF and the application of PBM. These combinations may be promising for skin tissue engineering. Therefore, the aim of this study was to investigate the viability, proliferation and cytotoxicity of a pristine BCM, and BCM-based with or without FGF-2 in association with PBM therapy. We hypothesized that fibroblasts in the membranes supplemented with FGF-2 and treated with PBM would present better viability and proliferation.

\section{Material and methods}

\subsection{Bacterial cellulose membrane}

The bacterial cellulose membranes (BCM) were obtained via culture of strains of the bacterium Komagataeibacter xylinus in HS (Hestrin-Schramm) culture medium, which has the following basic composition: $2 \%$ (m/v) glucose, $0.5 \%$ $(\mathrm{m} / \mathrm{v})$ peptone, $0.5 \%$ yeast extract, $0.27 \%(\mathrm{w} / \mathrm{v})$ anhydrous disodium phosphate and $0.115 \%$ (w/v) citric acid monohydrate [7]. After production, the wet membranes were purified in alkaline medium at $80^{\circ} \mathrm{C}$, for 40 minutes and washed with distilled water to neutral $\mathrm{pH}$. The wetted membranes ( $2 \mathrm{~mm}$ thickness) were refrigerated in a $70 \%$ alcohol flask until use. Before use, the membranes were cut by sterile surgical punch with diameter close to the culture plate well, washed and hydrated in distilled water. After, the hydrated membranes were soaked in Dulbecco's Modified Eagle Medium (DMEM) supplemented with 10\% Fetal Bovine Serum (SFB) and 1\% antibiotic-antimycotic solution. Afterwards, the membranes were sterilized on both sides, under laminar flow ultraviolet light for 3 hours each side. The 
cut and sterilized membranes were kept refrigerated until use, when they were environmentalized up to $37^{\circ} \mathrm{C}$ for $\mathrm{pH}$ and SEM evaluations and cell culture studies.

\subsection{BCM extract}

For Alamar Blue (using macrophages, J774A.1) and Comet assays (using fibroblasts, L929) the BCM extract was used. For this purpose, the BCM was dried inside the laminar flow until all $70^{\circ}$ alcohol evaporated. After that, the samples were weighed and incubated for 7 days in Dulbecco's Modified Eagle Medium (DMEM, Vitrocell, Campinas, SP, Brazil) (50 mL/g) [23] supplemented with 10\% fetal bovine serum (Vitrocell, Campinas, SP, Brazil) and 1\% antibioticantimycotic solution (Vitrocell, Campinas, SP, Brazil) at $37{ }^{\circ} \mathrm{C}$ in a humidified atmosphere of $5 \% \mathrm{CO}_{2}$.

\section{3. pH measurements}

Before starting the in vitro membrane assays, a pH evaluation was performed. For this, the circle's cut $\left(0,84 \mathrm{~cm}^{2}\right)$ hydrated membranes $(\mathrm{n}=5)$ were placed in $3 \mathrm{~mL}$ of phosphate buffered saline (PBS, $\mathrm{pH} 7.4)$, and incubated on a humidified incubator set at $37^{\circ} \mathrm{C}$ and $5 \% \mathrm{CO} 2$ [24]. The groups in this test were CG (control group) only PBS and BCM membrane incubated in PBS. Analyzes were performed before (day 0) and after incubation of membranes at days 3, 6, 9, 14 and 21. The samples were taken from the incubation and the pH was measured with a pH meter (Orion Star A211, Thermo Scientific, Massachusetts, USA). A curve was obtained for pH data after the incubation days.

\subsection{Scanning electron microscopy (SEM)}

For characterization of the BCM, the samples were dried at room temperature in a laminar flow cabinet and covered with coverslip [25]. Finally, the dried BCM membranes were mounted on carbon tapes and aluminum stubs, sputtercoated and analyzed by SEM at 1000x and 1200x magnification for checking the surface on both sides of the BCM.

\subsection{Cell lineage}

Murine fibroblasts (L929 - BCRJ, RJ, Brazil) were used in this study for all the cellular assays. Specifically, for Alamar Blue it was used two cellular linages: fibroblasts (L929) and macrophages (J774A.1) (BCRJ, RJ, Brazil). Both cellular linages were cultured in Dulbecco's Modified Eagle Medium (DMEM, Vitrocell, Campinas, SP, Brazil), supplemented with $10 \%$ fetal bovine serum (Vitrocell, Campinas, SP, Brazil) and 1\% antibiotic-antimycotic solution (Vitrocell, Campinas, $\mathrm{SP}$, Brazil) using a humidified incubator set at $37^{\circ} \mathrm{C}$ and $5 \% \mathrm{CO} 2$. The cells were kept at sub confluence and subcultivated every 2-3 days until use.

\subsection{Cell seeding on the membranes and experimental groups}

For both cell linage, upon $80 \%$ confluence cells were detached using trypsin and seeded in direct contact with the bacterial cellulose membrane at a density of $1,0 \times 10^{4}$ cells/well, using 48 -well plates which contained $500 \mu \mathrm{L}$ of DMEM per well, the point which distinguished each group was the DMEM enrichment or not with FGF-2, and treatment with PBM. Therefore, the experimental groups were: Control Group- pure DMEM without FGF enrichment or PBM treatment (CG); Group DMEM enriched with FGF-2 (BCM/FGF); Group with PBM treatment (BCM/PBM); Group enriched with FGF-2 and with PBM treatment (BCM/FGF+PBM).

The BCM/FGF and BCM/FGF+PBM groups received supplementation with $5 \mathrm{ng} / \mathrm{mL}$ of FGF-2 (Sigma-Aldrich®, USA), as previously described [12]. The groups BCM/PBM and BCM/FGF+PBM received PBM application. The cells were incubated during 1, 3, 6 and 9 experimental days for further analysis, as shown in Figure 1. For the comet assay, the density of $4 \times 10^{4}$ cells/well was used for fibroblasts, using 12-well plates which contained 2 mL of DMEM per well. 


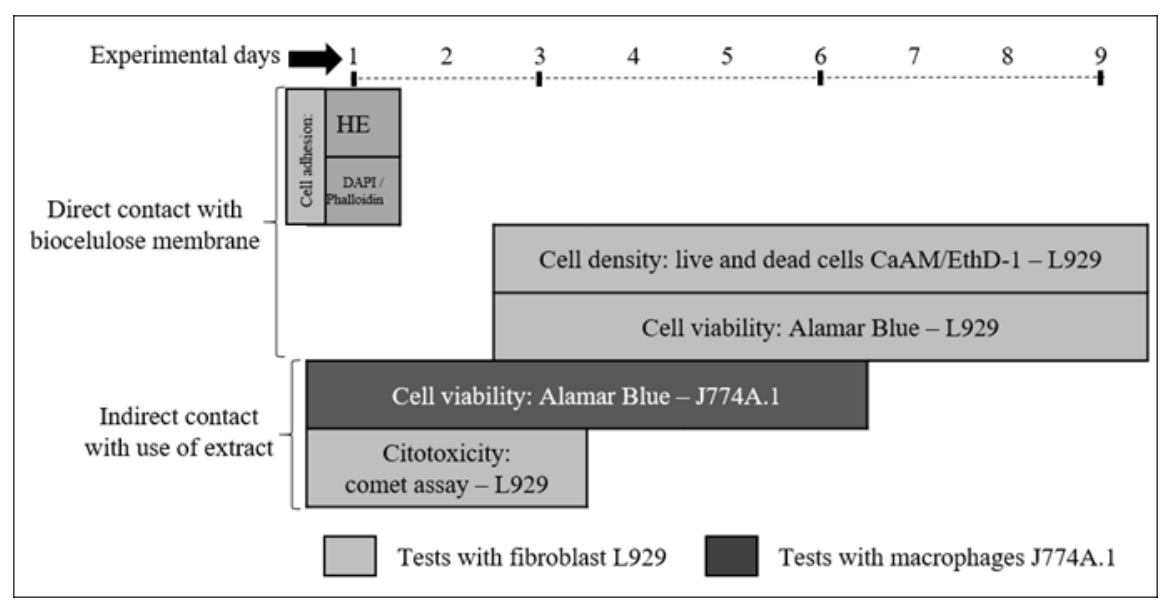

Figure 1 Representative scheme of the experimental part performed in vitro. The scheme contains the in vitro evaluations, from the tests with the membrane or extract of it, for the cell lines L929 and J774A.1, in the several experimental days.

\subsection{Photobiomodulation}

After every 24 hours of $\mathrm{L} 929$ seeding on the BCM membranes, the PBM was performed within the laminar flow at a single point in the center of each culture well (for BCM/PBM and BCM/FGF+PBM groups). The plates were kept at $1 \mathrm{~cm}$ away from the laser tip. For PBM therapy standardization, an irradiation support was created where the laser tip was fixed.

The PBM apparatus was placed outside the laminar flow, but its tip, previously sterilized, was placed inside the flow. The PBM was performed in the dark to minimize interference from ambient light. Still, all the other groups were subjected to these same handling conditions. For the PBM application, the portable DMC laser, class 3B Ga-Al-As diode (Equipamentos Ltda., Brazil) was used. The irradiation parameters used was [26-28]: Wavelength $660 \mathrm{~nm}$, Fluence 10 $\mathrm{J} / \mathrm{cm}^{2}$, Spot size $0.027 \mathrm{~cm}^{2}$, Treatment time $9 \mathrm{~s}$, Power output $30 \mathrm{~mW}$, Wave emission mode was continuous. The first irradiation was 24 hours post-seeding and after every 24 hours, until a total of 1,3 and 6 applications, according to the experimental time points.

\subsection{Histological staining hematoxylin eosin}

Two samples of BCM membranes seeded with cells were fixed with $10 \%$ buffered formaldehyde, washed with distilled water, cut in half, and frozen in liquid nitrogen. The samples were sections in cryostat $(10 \mu \mathrm{m})$ and the slides were stained with hematoxylin and eosin (HE) (Sigma Chemical Company, St. Louis, EUA) for visualization of cell adhesion and membrane layer thickness [29]. The objective 10x was used to this analysis. For this, a computerized image equipment (Axio Visio 4.5 Zeiss) attached to an optical microscope (Axio Observer D1, Zeiss) was utilized, and the photomicrographs were taken with a $5 x, 10 x$ and $20 x$ objective.

\subsection{Immunofluorescent DAPI and Phalloidin staining}

Fluorescent staining with DAPI and Phalloidin were used for identifying the L929 line cell nuclei and F-actin. Two samples of the membranes seeded with L929 cell line for each group and at all experimental periods were stained with DAPI/Phalloidin [29,30]. For this, the samples were washed with prewarmed PBS to remove the DMEM and serum, fixed in $4 \%$ formaldehyde solution in PBS, and washed with PBS again. The cells were permeabilized with $0.1 \%$ Triton X-100 in PBS, washed with PBS, incubated in Alexa Fluor 488 Phalloidin (Thermo Scientific, USA), protecting from light, for 20 minutes, and washed with PBS one more time. Subsequently to the procedures with Phalloidin staining, the samples were washed with PBS, and DAPI, 4', 6-diamidino-2'-phenylindole, dihydrochloride (in PBS 1:1000; Thermo Scientific, USA) was added for a 5-minutes incubation. After that, the samples were washed with and kept in PBS until fluorescence visualization. For this, a computerized image equipment (Axio Visio 4.5 Zeiss) attached to a fluorescence microscope (Axio Observer D1, Zeiss) was utilized, and the photomicrographs were taken with a 40x objective. 


\subsection{Immunofluorescent CaAM/EthD-1 staining}

For evaluation of density of fibroblast cells L929 seeded on BCM was used staining with Calcein AM/Ethidium homodimer-1 (CaAM/EthD-1), that provides two-color fluorescence cell, green for live and red for dead cells respectively. For this purpose, the samples were washed with prewarmed PBS to remove the DMEM and serum, fixed in methanol, washed with PBS one more time, and incubated with CaAM/EthD-1, LIVE/DEAD Viability/Cytotoxicity Kit (Thermo Fisher Scientific, USA). Approximately $200 \mu \mathrm{L}$ of the solution was added to the membranes, for 45 minutes, at room temperature and protecting from light [29].

The samples were analyzed under the optical microscope for morphometric analysis. For this purpose, the membranes were divided into four quadrants and two fields were photographed for each quadrant. Finally, the cells were counted, and the mean and standard deviation of the numbers of the cells present in each group were calculated [31]. For this, a computerized image equipment (Axio Visio 4.5 Zeiss) attached to a fluorescence microscope (Axio Observer D1, Zeiss) was used, and the photomicrographs were taken with a 20x objective.

\subsection{Alamar Blue}

After the experimental period of each group, the Alamar Blue (Thermo Fisher Scientific, São Paulo, Brazil) was performed in order to evaluate cell viability. For this, after each experimental period, the DMEM was discarded and the well plates were washed with phosphate buffered saline (PBS). Afterwards, $500 \mu \mathrm{l}$ of $10 \%$ Alamar Blue solution was added into each well of a 48-well plate and incubated in dark for 4 hours. Subsequently, $200 \mu \mathrm{l}$ of solution (in duplicate) were aliquoted into wells of a 96-well plate for the measurements in the microplate spectrophotometer (Bio-Tek Instruments, Inc.) at 570 and $600 \mathrm{~nm}$. From the values obtained, proliferation rates were calculated as the percentage reduction of Alamar Blue, according to manufacturer's instructions. This viability assay was performed in quadruplicate and in three independent experiments.

\subsection{Comet assay}

For Comet assay was performed to verify BCM cytotoxicity [32,33]. After the experimental periods, the well plates were washed with PBS, the cells were trypsinized and put into a $50 \mathrm{~mL}$ flask. The flasks were centrifuged at $1200 \mathrm{rpm}$ for 4 min. After, the DMEM was removed, and the cells were resuspended with $1 \mathrm{~mL}$ fresh DMEM. Subsequently, $100 \mu \mathrm{L}$ DMEM was added to $120 \mu \mathrm{L} \mathrm{0.5 \%} \mathrm{low} \mathrm{melting-point} \mathrm{agarose} \mathrm{(Invitrogen,} \mathrm{USA).} \mathrm{The} \mathrm{samples} \mathrm{were} \mathrm{placed} \mathrm{onto} \mathrm{a} 1.5 \%$ agarose-precoated slide and covered with a coverslip. The agarose solidification was made inside the freezer, the coverslip was removed, and the slides were incubated in lysis solution for $1 \mathrm{~h}$ [ $2.5 \mathrm{M} \mathrm{NaCl}, 100 \mathrm{mM}$ EDTA (Merck, USA), $10 \mathrm{mM}$ Tris-HCl buffer, pH 10 (Sigma-Aldrich, USA),1\% sodium sarcosinate (Sigma-Aldrich, USA), with 1\% Triton X100 (Sigma-Aldrich, USA) and 10\% dimethyl sulphoxide (Merck)]. After that, the slides were immersed in alkaline buffer [0.3 mM NaOH (Merck) and $1 \mathrm{mM}$ EDTA, $\mathrm{pH}>13$ (Merck)] for $20 \mathrm{~min}$. The electrophoresis was done for $20 \mathrm{~min}$ at $25 \mathrm{~V}$ $(0.86 \mathrm{~V} / \mathrm{cm})$ and $300 \mathrm{~mA}$. The slides were neutralized in $0.4 \mathrm{M}$ Tris- $\mathrm{HCl}, \mathrm{pH} 7.5$, and fixed in $100 \%$ ethanol (Merck, Darmstadt, Germany). The stain was made with UniSafe Dye Nucleic Acid Staining Solution (Uniscience Corporation, USA), according to manufacturer's instructions. The analysis of 50 comets/material/period was done using an objective of40x[34]. For this analysis, a computerized image equipment (Axio Visio 4.5 Zeiss) attached to a fluorescence microscope (Axio Observer D1, Zeiss) was used. The level of DNA damage was measured by calculating the tail moment with the Comet Score 2.0software (TriTek Corp., USA).

\subsection{Statistical analysis}

Data were expressed as mean \pm standard deviation (SD) of the mean and $p \leq 0.05$ was considered to be statistically significant. The normality of all variable's distribution was verified using the Shapiro-Wilk test. For parametric data, analysis of variance (ANOVA), with two factors and Tukey's post test were used for multiple comparisons among groups. For nonparametric data, the Kruskal-Wallis test and post hoc Dunn were used. Prism 8 software (GraphPad, USA) was used to perform statistics analysis. 


\section{Results}

\subsection{Physical-chemical Characterization of pristine BCM}

\subsection{1. $p H$}

Figure 2 demonstrates the $\mathrm{pH}$ values measured for CG and BCM for up to 21 days. For both groups, a pH drop was observed after three days, with values going from $\sim 7.5$ to $\sim 6.7$. After this, plateaus were reached with values between 6.5 and 6.7 till the last experimental periods. It was verified that the first experimental day (day 0) presented pH values statistically higher than the other experimental periods ( $p>0.05)$.

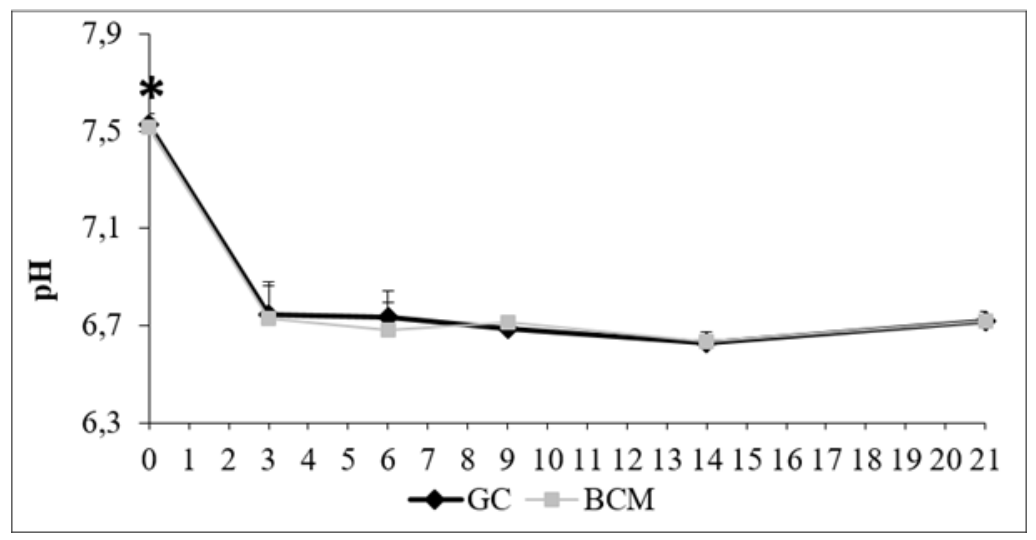

Figure $2 \mathrm{pH}$ values for $\mathrm{CG}$ and $\mathrm{BCM}$ groups after incubation in PBS at different times (1, 3, 6, 9, 14 and 21 days). The asterisk indicates $p \leq 0.0001$.

\subsubsection{SEM}

By SEM evaluation, it could be observed that the membrane has two distinct phases (one each side).One of them had a more dense appearance (Figure 3A) while the other was more fibrous (Figure 3B).
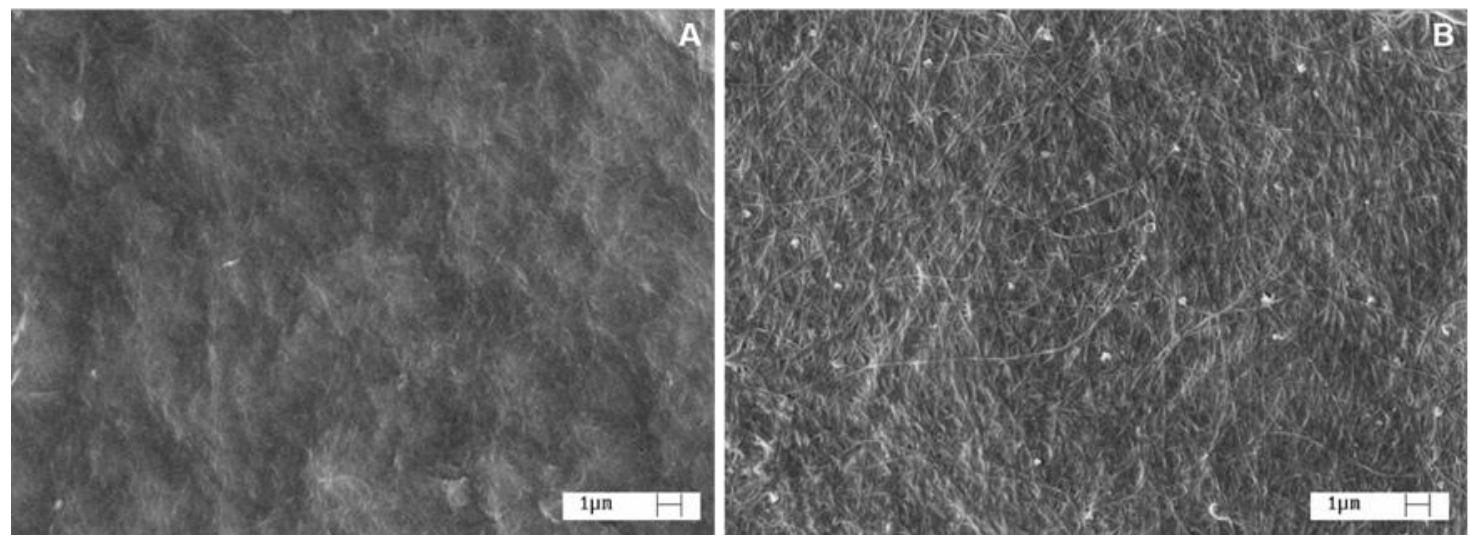

Figure 3 SEM micrographs of both phases of the BCM. In A, the dense side of the membrane is shown and in B the more fibrous side.

\subsection{Evaluation in vitro}

\subsubsection{Cell adhesion: Hematoxylin eosin staining}

The analysis of HE staining of the BCM membrane showed that the same has three distinct layers: the two lateral layers present a more narrow appearance, on which L929 cells adhered, and the central layer is the thickest one (Figure 4A). The cells adhered in the thinner and porous membrane layers, deepening through these lateral layers (Figure 4B). 


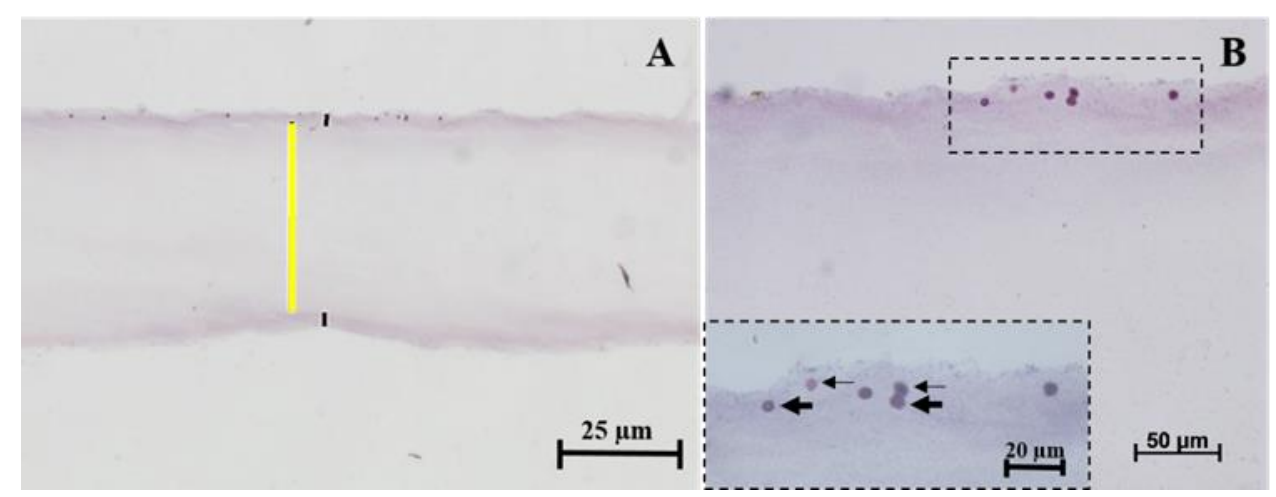

Figure 4 Bacterial cellulose membrane after L929 cell seeding and staining with HE. In A, the three layers of membrane could be observed; black line represents the thinner lateral layers of the membranes and yellow line the thicker central layer. In B, adhered cells at different depths of the membrane lateral layers (higher magnification in the dashed box).

\subsubsection{Cell adhesion: DAPI/Phalloidin immunofluorescent staining}

DAPI/Phalloidin staining evaluation showed that L929 cells were adhered all over the lateral layers of membrane (Figure 5A). By using higher magnifications, cells could be found adhered on the surface of the BCM and to different depths (Figure 5B).
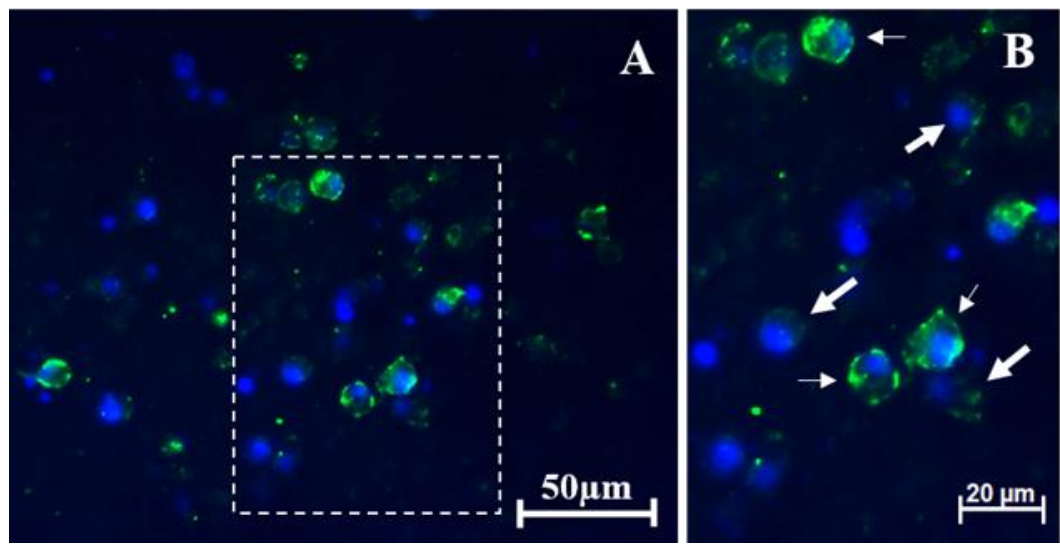

Figure 5 Bacterial cellulose membrane after L929 cell seeding and staining with fluorescent DAPI and Phalloidin. In A, adhered cells all over the lateral layers of the BCM. In B, cells could be found adhered to different depths of the membrane (cells on the surface of the biomaterial are pointed out with thin arrows and deeper cells are pointed out with thick arrows).

\subsubsection{Cell density: live and dead cells}

In qualitative analysis of the immunofluorescent staining with CaAM/EthD-1, for live and dead cell, it was possible to observe the presence of fewer cell intensity on day 3 and a greater amount on days 6 and 9, independent if dead or live cells (Figure 6A-L). For the live cells (in green), on the 9th experimental day, an intense amount of these cells was observed in the BCM/PBM and BCM/FGF+PBM groups, when observed the other groups (Figure 6K-L). Regarding dead cells (in red), on day 3 the BCM group (Figure 6A) and on the other experimental periods ( 6 and 9 days), regardless of the groups (Figure 6E-L), dead cells were observed in a similar amount. 


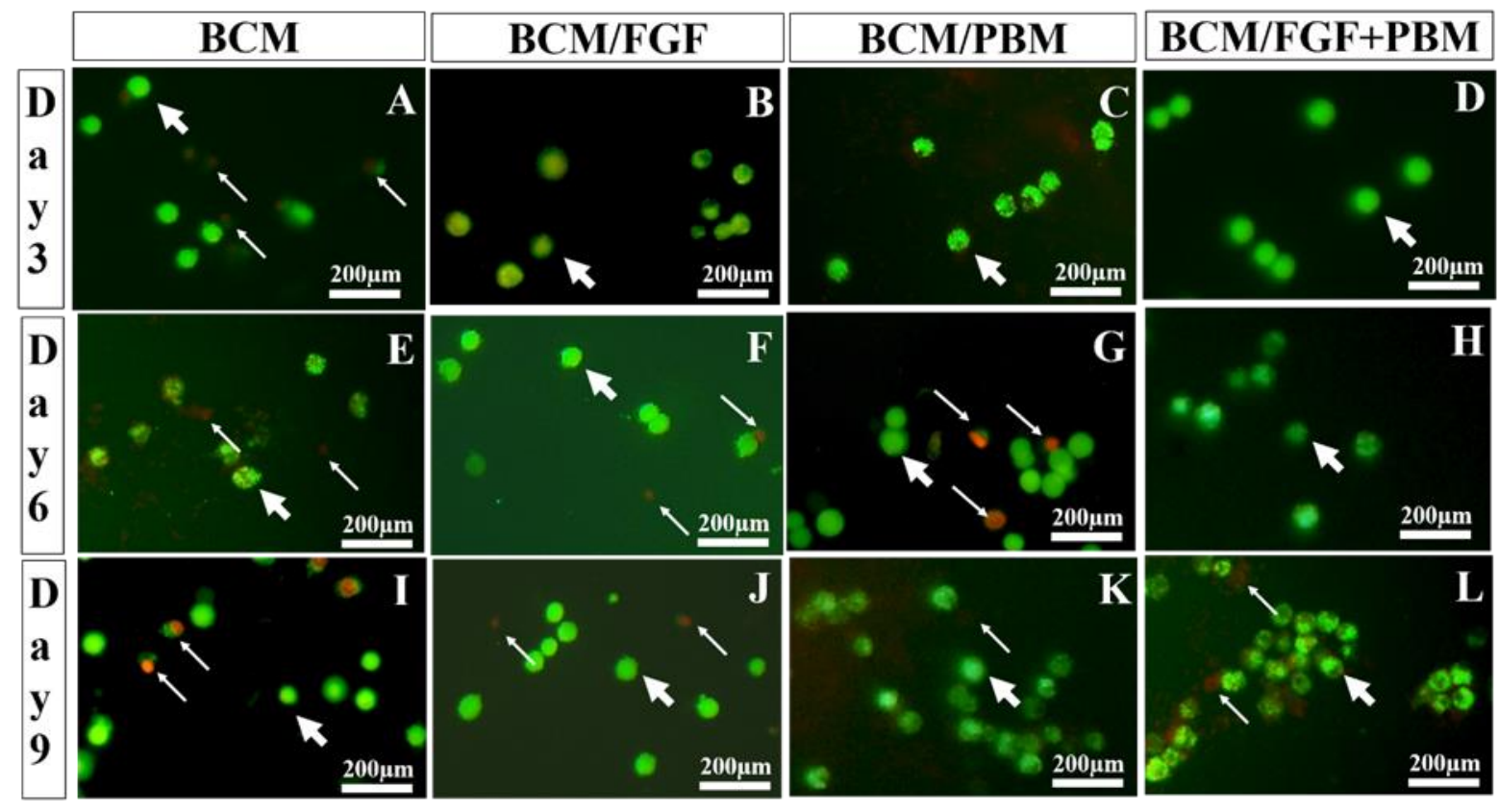

Figure 6 Immunofluorescent staining with CaAM/EthD-1 of the fibroblasts adhered on the membrane. Live cells are stained in green (thick arrows) and dead cells stained in red (thin arrows). The photomicrographs belong to the BCM (A, E and I), BCM/FGF (B, F and J), BCM/PBM (C, G and K) and BCM/FGF+PBM (D, H and L) groups evaluated at days 3, 6 and 9. K-L more live cells. B-D there are almost no dead cells. Scale bars $=200 \mu \mathrm{m}$.

Morphometry of the density of live and dead fibroblasts stained with CaAM/EthD-1, it was verified a progressive increase in the density of live fibroblasts for all groups overtime, and this number was higher for BCM/FGF+PBM compared to BCM/FGF and BCM at day $9(p \leq 0.05$; Figure 7A). Considering the density of dead fibroblasts, at day 3, this counting was statistically higher in BCM than in all other groups ( $p \leq 0.05$, Figure $7 \mathrm{~B})$. No other statistical difference was found among groups at any time point ( $p>0.05$, Figure 7B).

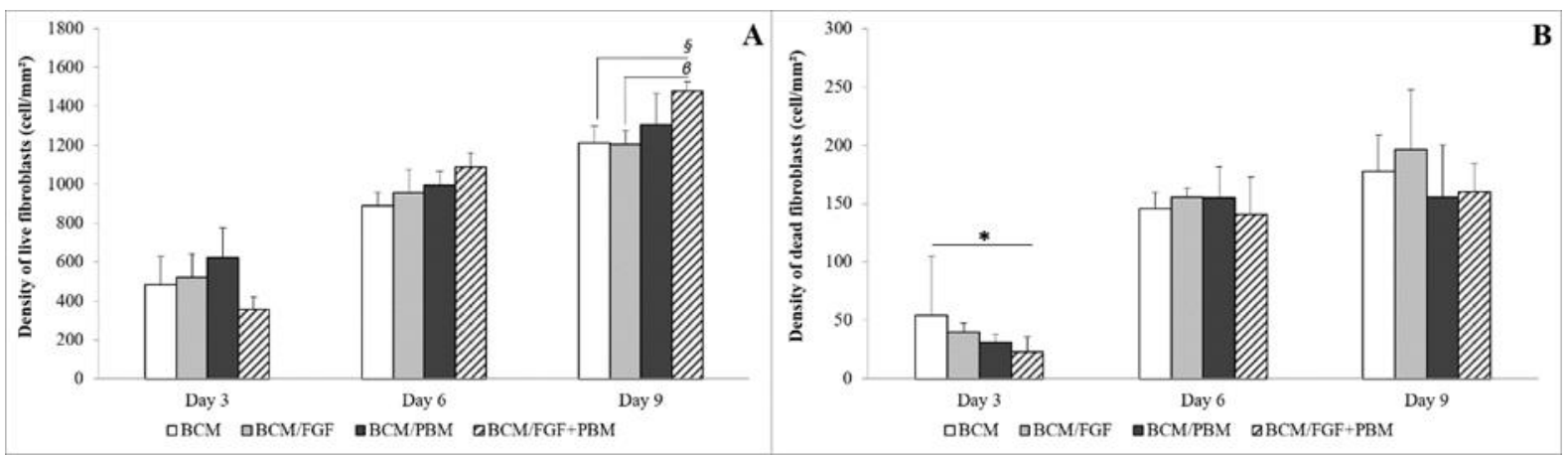

Figure 7 Mean + SD of density of live and dead fibroblasts stained with CaAM/EthD-1 on BCM after 3, 6 and 9 days of culture. In $\mathrm{A}, \xi \mathrm{BCM} / \mathrm{FGF}+\mathrm{PBM}$ vs. BCM $(p=0.0475)$ and $\beta \mathrm{BCM} / \mathrm{FGF}+\mathrm{PBM}$ vs. $\mathrm{BCM} / \mathrm{FGF}(p=0.0411)$. In $\mathrm{B},{ }^{*} \mathrm{BCM}$ vs. $\mathrm{BCM} / \mathrm{FGF}(p=0.0155)$, vs. BCM/PBM $(p=0.0028)$ and vs. BCM/FGF+PBM $(p=0.0028)$.

\subsubsection{Cell viability: Alamar Blue}

Investigation of the viability on L929 cells in direct contact with BCM by Alamar Blue showed that, at day 3, the cell viability was higher for BCM/FGF+PBM compared to BCM/FGF and CG $(p \leq 0.05)$. And BCM/PBM was higher than $\mathrm{BCM} / \mathrm{FGF}$ and CG $(p \leq 0.05)$. Additionally, at day 6 cell viability was higher for BCM/FGF+PBM compared to all other groups $(p \leq 0.05)$. After 9 days of culture, no statistical difference was detected among groups (Figure 8). 


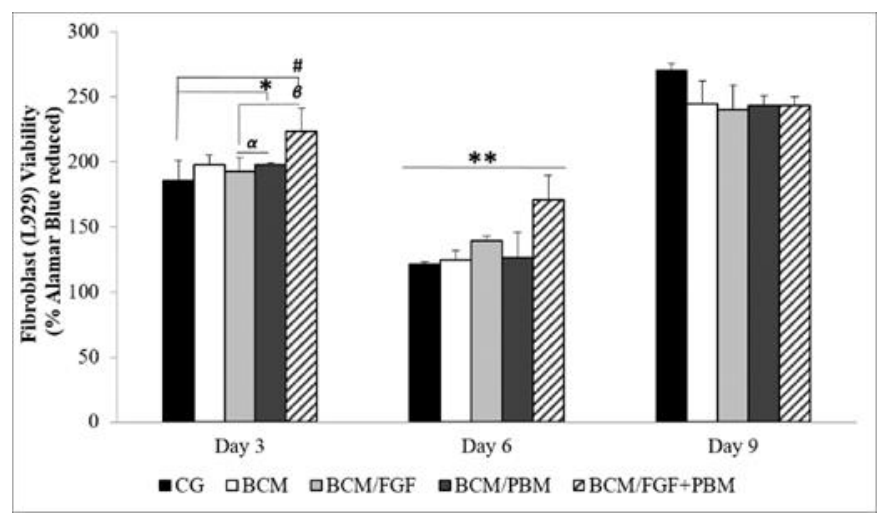

Figure 8 Mean + SD of L929 for Alamar Blue viability on the bacterial cellulose membranes after 3, 6 and 9 days of culture by direct contact. At 3 days, * BCM/PBM vs. CG ( $p=0.0003) ; \# \mathrm{BCM} / \mathrm{FGF}+\mathrm{PBM}$ vs. CG $(p=0.0098) ; \alpha \mathrm{BCM} / \mathrm{PBM}$ vs. $\mathrm{BCM}(p=0.0017) ; \beta \mathrm{BCM} / \mathrm{PBM}$ vs. BCM/FGF ( $p=0.0008) ; \mu \mathrm{BCM} / \mathrm{FGF}+\mathrm{PBM}$ vs. BCM/FGF $(p \leq 0.00281)$. At 6 days, ** $\mathrm{BCM} / \mathrm{FGF}+\mathrm{PBM}$ vs. CG $(p=0.0011)$, vs. BCM (0.0018), vs. BCM/FGF $(p=0.0428)$ and vs. BCM/PBM $(p=0.047)$.

The viability evaluation for indirect contact on J774A.1 cells by Alamar Blue showed that, at day 1, CG was higher than BCM and BCM/FGF. Still after 1 day of culture, BCM/PBM and BCM/FGF+PBM was statistically higher than BCM. Additionally at the same period, BCM/PBM and BCM/FGF+PBM was higher than to BCM/FGF (Figure 9).

At days 3, the cell viability was statistically higher for CG than BCM/FGF and BCM/FGF+PBM, and finally BCM/FGF was lower than BCM and BCM/PBM. After 6 days of culture, no statistical differences was detected among groups (Figure 9).

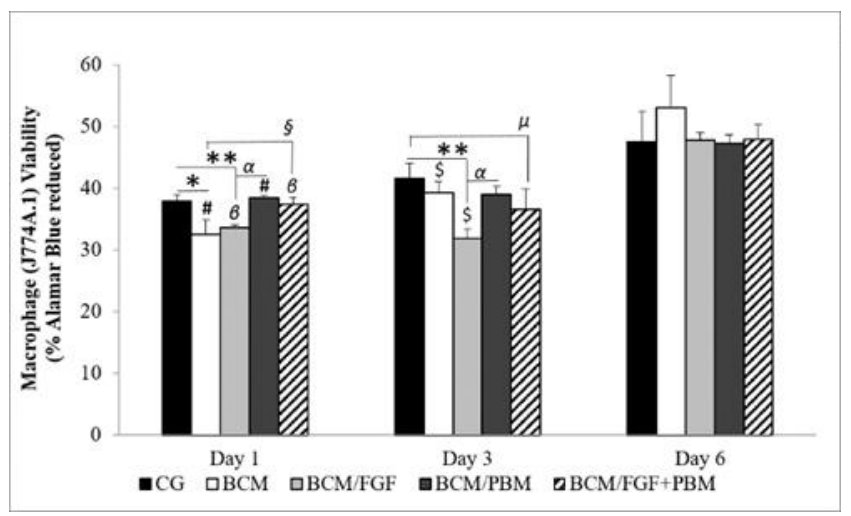

Figure 9 Mean + SD of J774A.1 for Alamar Blue viability on the bacterial cellulose membranes after 1, 3 and 6 days of culture by indirect contact. *BCM vs. CG ( $p=0.0013)$; ${ }^{* *} \mathrm{BCM} / \mathrm{FGF}$ vs. CG $(p=0.0069)$; \# BCM/PBM vs. BCM $(p=0.0003)$; $\S \mathrm{BCM} / \mathrm{FGF}+\mathrm{PBM}$ vs. BCM $(p=0.0017 ; \alpha \mathrm{BCM} / \mathrm{PBM}$ vs. BCM/FGF $(p=0.0017) ; \beta \mathrm{BCM} / \mathrm{FGF}+\mathrm{PBM}$ vs. $\mathrm{BCM} / \mathrm{FGF}(p=0.01)$.

\subsubsection{Cytotoxicity: Comet assay}

By using single-cell gel assay (Comet), the DNA damage in fibroblast cells was quantified via calculation of the tail moment. No statistical difference ( $p>0.05)$ was found among groups at days 1 and 3 of cell culture (Table 1 ).

Table 1 Mean \pm SD of fibroblast DNA damage (tail moment; $p>0.05$ )

\begin{tabular}{|l|l|l|l|l|l|}
\hline & \multicolumn{5}{|l|}{ Experimental groups } \\
\hline Days & CG & BCM & BCM/FGF & BCM/PBM & BCM/FGF+PBM \\
\hline 1 & $0.90 \pm 0.53$ & $1.92 \pm 1.12$ & $1.29 \pm 0.95$ & $1.08 \pm 0.23$ & $1.76 \pm 1.04$ \\
\hline 3 & $0.97 \pm 0.49$ & $1.37 \pm 0.79$ & $0.72 \pm 0.51$ & $0.60 \pm 0.19$ & $0.68 \pm 0.48$ \\
\hline
\end{tabular}




\section{Discussion}

The healing process of extensive or deep burns and chronic skin injuries is complex and its initial period is critical for proper healing [35]. In order to speed up and control the regeneration process, it is recommended to treat the injury with an appropriate curative wound dressing [36,37]. The curatives that play these roles can be foams, polymeric films or membranes. Often it may be bioactive, containing added drugs or tissue growth factors $[37,38]$. Specifically, the BCM from bacteria has been widely used for various medical applications, principally curatives in membranes or films format [39]. Therefore, this study, we used the BCM obtained by cultivating of the bacteria Komagataeibacter xylinus together with FGF-2 in association with the treatment by PBM, in order to characterize the BCM by pH variation, topography and structure. In addition, we verified the cell adhesion, density of live and dead cells, viability and cytotoxicity of fibroblasts cultured on this BCM. And also evaluated the viability of macrophages in contact with the BCM extract. It is still necessary to clarify that we stated for this study, treatments with PBM or/and FGF-2 at short-term we considered until 3 days, and long-term 9 days, while that the period 6 days was an intermediate time.

One of the means for characterizing BCM was the evaluation of $\mathrm{pH}$ over time, which showed no statistical difference between the Control and BCM groups. At day 3, the values dropped from 7.5 to approximately 6.7, when a plateau was reached, remaining stable until the end of the experimental periods. Even with this $\mathrm{pH}$ variation, the cells were still viable and proliferating, leading to no damage to cells growth on the membrane or in the presence of the extracts. The study of Kruse et al. [40] verified in vitro the effect of different $\mathrm{pH}$ levels on the fibroblast culture. This work corroborates our findings, because they demonstrated that in a neutral environment ( $\mathrm{pH} 6.6$ to 8.0) there was a significant increase in cell proliferation of fibroblasts. However, the physiological pH of the stratum corneum is among 4.1-5.8 [41]. In this context, health care products of the skin that to act in the maintaining of the acidic $\mathrm{pH}(\cong 4.0-5.0)$ is beneficial for epidermal physiology and cutaneous microflora. , cleansing and skin with a $\mathrm{pH}$ level of may be helpful [42].

Still about the characterization of pristine BCM, it was detected by SEM analysis that the membrane has two sides, one apparently denser and the other more porous. So, for the fibroblasts to adhere on the BCM, it was necessary to seed the cells onto the porous side. Through SEM, other studies with BCM found a characterization similar to that found in the BCM of this study, it clearly presents a more compact surface and another one composed of long fibers with nanometer thickness [43-47]. Accordingly, Kaur et al. previously verified that cells were able to adhere more easily in thinner and porous BCM layers and, from there, they may go deeper along the membrane [2].

In this study, cell adhesion was verified by two analyzes, histological by HE staining and fluorescence staining of DAPI/Phalloidin, which marks the nucleus in blue and the cytoplasm in green. These analyzes allowed to verify that the cells were adhered to the membrane at different depths, with some in deeper layers and others more superficial (Figures 4 and 5). The fluorescence of DAPI/Phalloidin allowed a superior view of the adhesion of the cells in the membrane. However, HE staining was done by cutting the membrane longitudinally, making it possible to observe cells at different depths in addition to the membrane layers, which were previously characterized by SEM analysis. Romano et al. [29] evaluated cell adhesion by HE and DAPI/Phalloidin staining in order to verify the survival of endothelial cells on a membrane endothelial. The authors state that in the case of cell transplants on the membrane, the survival of the cells is a factor of great importance. The study of Romano and collaborators corroborates our study, as HE staining allowed the visualization of cell nucleus at different depths of the membrane in paraffin section and by DAPI/Phalloidin cells were seen at different depths of the membrane surface.

Related to the adhesion of fibroblasts to the BCM, we verified by SEM that there is formation of pores that probably enable the adhesion of cells. Accordingly, by the evaluation of HE and DAPI / Phalloidin stains, we observed that cells adhered onto the membrane surface layers. Therefore, we suggest the use of BCM, cell culture, supplementation with FGF-2 and application of PBM as a possibility for dressing in in vivo models of skin injuries, such as burn injuries or skin flap. According to recent studies, cell adhesion in a membrane-type dressing becomes important for the treatment of skin injury accelerating regeneration, increasing cell migration, differentiation and proliferation [39,48,49].

By analyzing the density of live and dead cells, it was possible to observe that on last experimental day, the long-term combined treatment favored the survival of fibroblast on the membrane, because this group presented the density of live cells higher compared to the other groups. While at short-term, on day 3 experimental, the number of dead fibroblasts was higher in the group with any treatment when compared to all other groups with some type of treatment, either PBM, FGF or both combined. With these facts, we may affirm that the combined treatments favored a greater cell survival over time, short- or long-term, different of the separated treatments that improved the survival only at shortterm. 
For comparison with our study, no studies were found in the literature that evaluated both PBM and FGF treatments. However, regarding the treatment at short-term with FGF-2, in an in vitro study that treated mouse fibroblasts with this factor, the researchers found that it promoted fibroblast proliferation after $24 \mathrm{~h}$, which in the case of wound healing is very important [50]. Other in vitro study investigated the PBM in vitro, L929 mouse fibroblast were exposed with 635 $\mathrm{nm}$ laser irradiations of 1 and $3 \mathrm{~J} / \mathrm{cm}^{2}$ energy densities at $50 \mathrm{~mW}$ output power separately. Viabilities of cells were examined by means of MTT assays performed at the 24th, 48th, and 72nd hours following PBM. MTT assay results that both energy densities after $24 \mathrm{~h}$ and $72 \mathrm{~h}$ were found to be proliferative [51].

Regarding viability (Alamar Blue), the PBM also presented beneficial effects for fibroblasts and macrophages in the initial experimental periods, at short-term, in our study this occurred especially when in association with FGF-2. The most critical period in the process of regeneration of a skin injury is the initial one, in which there is greater activity of inflammatory cells [52]. Additionally, in this study we checked that the period of greatest viability in BCM, with the association of the two treatments, occurred in a short-term up to 6 days for both inflammatory macrophage cells and fibroblasts.

Then, when thinking about the use of this association of BCM and the two treatments used here, it can be suggested that they could contribute to the repair process of skin injuries in a clinical context. It is interesting to note that it is in this short-term that there is an increase in the expression of growth factors responsible for the chemical stimuli of cell migration, which are necessary for the next steps of healing and re-epithelization of the skin injury [52]. Still in relation to viability, but now referring to long-term, 9 days for fibroblasts and 6 days for macrophages, the treatment efficiency was not so evident. Since we did not find a statistical difference in cell viability for this period.

An in vitro study established cellular responses to Helium-Neon (632.8 nm) PBM using different fluencies (0.5 to 16 $\mathrm{J} / \mathrm{cm}^{2}$ ) on human skin fibroblasts, with one exposure for 2 days. The authors verified that lower fluency had better responses to cell proliferation and cell viability. And the two higher doses decreased this both parameters, also promoted damage to cell DNA [53]. This study is not in accordance with our findings, because until the third experimental day we verified beneficial effects of PBM on cell viability and proliferation with greater fluency of $10 \mathrm{~J} / \mathrm{cm}^{2}$. Furthermore, cytotoxicity was not observed in this fluency even after 9 days of daily treatment.

Wherefore, it is possible to observe that BCM from the Komagataeibacter xylinus bacterium has shown to be promising for using in the medical field. The membrane has good cytocompatibility, allowing cell adhesion and causing no damage to the cells' DNA. It is also worth mentioning that the application of FGF-2 and PBM, in combination with the BCM, showed promising results for cytoviability and density of living cells. Although the present results indicate that the use of the bacterial cellulose membrane combined with cells, growth factor and photobiomodulation is feasible and promising for the application in the context of skin injuries, further tests need to be done in in vivo models for verifying this clinical potential toward healthcare applications.

\section{Conclusion}

Bacterial cellulose membranes obtained from Komagataeibacter xylinus bacterium and characterization tests showed that these biomaterials presented stable $\mathrm{pH}$ (close to the physiological one), and porous/fibrous aspect. Additional evaluations indicated cell adhesion, specially, through the porous side of the membrane. Moreover, in vitro studies indicated that the BCM in combination with FGF-2 and PBM were not cytotoxic. By using fibroblasts and macrophages, it could be observed increased viability, mainly for BCM/FGF+PBM compared to other groups at days 1 and 3 of culture. Taken together, the present results show feasible and promising utilization of the BCM combined with FGF and PBM for biomedical applications. Still, further in vivo tests, using different animal models and longer time-points are necessary to elucidate and validate the utilization of this new therapeutic approach in the context of skin and burn injuries.

\section{Compliance with ethical standards}

\section{Acknowledgments}

The authors would like to thank the funding agencies for this work: São Paulo Research Foundation (FAPESP) grant numbers 2015/20704-8, 13/07276-1, 2018/25512-8; and the National Council for Scientific and Technological Development (CNPQ) grant number 407822/2018-6.

\section{Disclosure of conflict of interest}

The authors declare no conflict of interest. And all authors have made substantial contributions to the article. 


\section{References}

[1] Brassolatti P, Bossini PS, Kido HW, Derencio Oliveira MC, Almeida-Lopes L, Zanardi LM, Napolitano MA, Avó LRS, Araújo-Moreira FM, Parizotto NA. Photobiomodulation and bacterial cellulose membrane in the treatment of third-degree burns in rats. Journal of Tissue Viability. 2018; 27: 249-256.

[2] Kaur A, Midha S, Giri S, Mohanty S. Functional skin grafts: Where biomaterials meet stem cells. Stem Cells International. 2019; (1286054): 1-20.

[3] Savoji H, Godau B, Hassani MS, Akbari M. Skin Tissue Substitutes and Biomaterial Risk Assessment and Testing. Frontiers in Bioengineering and Biotechnology. 2018; 6(86): 1-18.

[4] de Oliveira Barud HG, da Silva RR, da Silva Barud H, Tercjak A, Gutierrez J, Lustri WR, de Oliveira-Junior OB, Ribeiro SJL. A multipurpose natural and renewable polymer in medical applications: Bacterial cellulose. Carbohydrate Polymers. 2016; 153: 406-420.

[5] Da LC, Huang YZ, Xie HQ. Progress in development of bioderived materials for dermal wound healing. Regenerative Biomaterials. 2017; 4(5): 325-334.

[6] Volova TG, Prudnikova SV, Sukovatyi AG, Shishatskaya EI. Production and properties of bacterial cellulose by the strain Komagataeibacter xylinus B-12068. Applied Microbiology and Biotechnology. 2018; 102(17): 7417-7428.

[7] Machado RTA, Gutierrez J, Tercjak A, Trovatti E, Uahib FGM, Moreno G de P, Nascimento AP, Berreta AA, Ribeiro SJL, Barud HS. Komagataeibacter rhaeticus as an alternative bacteria for cellulose production. Carbohydrate Polymers. 2016; 152: 841-849.

[8] Qiu Y, Qiu L, Cui J, Wei Q. Bacterial cellulose and bacterial cellulose-vaccarin membranes for wound healing. Materials Science and Engineering. 2016; 59: 303-309.

[9] Celes FS, Trovatti E, Khouri R, Van Weyenbergh J, Ribeiro SJL, Borges VM, Barud HS, de Oliveira CI. DETC-based bacterial cellulose bio-curatives for topical treatment of cutaneous leishmaniasis. Scientific Reports. 2016; 6: 38330.

[10] Fu L, Zhang J, Yang G. Present status and applications of bacterial cellulose-based materials for skin tissue repair. Carbohydrate Polymers. 2013; 92(2): 1432-1442.

[11] Martignago CCS, Tim CR, Assis L, Neves LMG, Bossini PS, Renno AC, Avo LRS, Liebano RE, Parizotto NA. Comparison of two different laser photobiomodulation protocols on the viability of random skin flap in rats. Lasers in Medical Science. 2019; 34(5): 1041-1047.

[12] Yanagita M, Kojima Y, Kubota M, Mori K, Yamashita M, Yamada S, Kitamura M, Murakami S. Cooperative effects of FGF-2 and VEGF-A in periodontal ligament cells. Journal of Dental Research. 2014; 93(1): 89-95.

[13] Yang J, Zhang D, Yu Y, Zhang RJ, Hu XL, Huang HF, Lu YC. Binding of FGF2 to FGFR2 in an autocrine mode in trophectoderm cells is indispensable for mouse blastocyst formation through PKC-p38 pathway. Cell Cycle. 2015; 14(20): 3318-3330.

[14] Yu A, Matsuda Y, Takeda A, Uchinuma E, Kuroyanagi Y. Effect of EGF and bFGF on fibroblast proliferation and angiogenic cytokine production from cultured dermal substitutes. Journal of Biomaterials Science, Polymer Edition. 2012; 23(10): 1315-1324.

[15] Avci P, Gupta A, Sadasivam M, Vecchio D, Pam Z, Pam N, Hamblin MR. Low-level laser (light) therapy (LLLT) in skin: Stimulating, healing, restoring. Seminars in Cutaneous Medicine and Surgery. 2013; 32(1): 41-52.

[16] Chaves ME de A, Piancastelli ACC, de Araújo AR, Pinotti M. Effects of low-power light therapy on wound healing: LASER x LED. Anais Brasileiros de Dermatologia. 2014; 89(4): 616-623.

[17] Gerbi MEM, Marques AMC, Ramalho LMP, Ponzi EAC, Carvalho CM, Santos RDC Oliveira PC, Nóia M, d Pinheiro ALB. Infrared laser light further improves bone healing when associated with bone morphogenic proteins: an in vivo study in a rodent model. Photomedicine and Laser Surgery. 2008; 26(1): 55-60.

[18] Vladimirov YA, Osipov AN, Klebanov GI. Photobiological principles of therapeutic applications of laser radiation. Biochemistry. 2004; 69(1): 81-90.

[19] De Freitas LF, Hamblin MR. Proposed Mechanisms of Photobiomodulation or Low-Level Light Therapy. IEEE Journal on Selected Topics in Quantum Electronics. 2016; 22(3): 7000417. 
[20] Hamblin MR. Mechanisms and applications of the anti-inflammatory effects of photobiomodulation. AIMS Biophysics. 2017; 4(3): 337-361.

[21] das Neves LMS, Leite G de PMF, Marcolino AM, Pinfildi CE, Garcia SB, de Araújo JE, Guirro ECO. Laser photobiomodulation (830 and $660 \mathrm{~nm}$ ) in mast cells, VEGF, FGF, and CD34 of the musculocutaneous flap in rats submitted to nicotine. Lasers in Medical Science. 2017; 32(2): 335-341.

[22] Lins RDAU, Dantas EM, Lucena KCR, Catão MHCV, Granville-Garcia AF, Carvalho Neto LG. Efeitos bioestimulantes do laser de baixa potência no processo de reparo. Anais Brasileiros de Dermatologia. 2010; 85(6): 849-855.

[23] Fernandes KR, Magri AMP, Kido HW, Parisi JR, Assis L, Fernandes KPS, Mesquita-Ferrari RA, Martins VC, Plepis AM, Zanotto ED, Peitl O, Renno ACM. Biosilicate/PLGA osteogenic effects modulated by laser therapy: In vitro and in vivo studies. Journal of Photochemistry and Photobiology B, Biology. 2017; 173: 258-265.

[24] Parisi JR, Fernandes KR, Avanzi IR, Dorileo BP, Santana AF, Andrade AL, Gabbai-Armelin PR, Fortulan CA, Trichês ES, Granito RN, Renno ACM. Incorporation of Collagen from Marine Sponges (Spongin) into Hydroxyapatite Samples: Characterization and In Vitro Biological Evaluation. Marine Biotechnology. 2019; 21(1): 30-37.

[25] Gabbai-Armelin PR, Kido HW, Cruz MA, Prado JPS, Avanzi IR, Custódio MR Renno ACM, Granito RN. Characterization and Cytotoxicity Evaluation of a Marine Sponge Biosilica. Marine Biotechnology. 2019; 21(1): 65-75.

[26] Machado AHA, Braga FMP, Pacheco Soares C, Pelisson MMM, Beltrame M, Da Silva NS. Photodynamic therapy with a new photosensitizing agent. Photomedicine and Laser Surgery. 2007; 25(3): 220-228.

[27] Szezerbaty SKF, de Oliveira RF, Pires-Oliveira DAA, Soares CP, Sartori D, Poli-Frederico RC. The effect of low-level laser therapy $(660 \mathrm{~nm})$ on the gene expression involved in tissue repair. Lasers in Medical Science. 2018; 33(2): 315-321.

[28] Marques JM, Pacheco-Soares C, Da Silva NS. Evaluation of the photobiomodulation in L929 cell culture. Experimental Biology and Medicine. 2014; 239(12): 1638-1643.

[29] Romano V, Parekh M, Ruzza A, Willoughby CE, Ferrari S, Ponzin D, Kaye SB, Levis HJ. Comparison of preservation and transportation protocols for preloaded Descemet membrane endothelial keratoplasty. British Journal of Ophthalmology. 2018; 102(4): 549-555.

[30] Wang X, Shi H, Cui J, Bai W, He W, Shang H, Su Y, Xin J, Jing X, Zhu B. Preliminary research of relationship between acute peritonitis and celiac primo vessels. Evidence-Based Complementary and Alternative Medicine. 2013; 569161.

[31] Min BM, Lee G, Kim SH, Nam YS, Lee TS, Park WH. (2004). Electrospinning of silk fibroin nanofibers and its effect on the adhesion and spreading of normal human keratinocytes and fibroblasts in vitro. Biomaterials. 2004; 25(78): $1289-1297$.

[32] Tice RR, Agurell E, Anderson D, Burlinson B, Hartmann A, Kobayashi H, Miyamae Y, Rojas E, Ryu JC, Sasaki YF. Single Cell Gel / Comet Assay : Guidelines for In Vitro and In Vivo Genetic Toxicology Testing. Environmental and Molecular Mutagenesis. 2000; 35(3): 206-221.

[33] Wang Y, Musich PR, Cui K, Zou Y, Zhu M-Y. Neurotoxin-induced DNA damage is persistent in SH-SY5Y cells and LC neurons. Neurotoxicity Research. 2015; 27(4): 368-383.

[34] Kido HW, Ribeiro DA, De Oliveira P, Parizotto NA, Camilo CC, Fortulan CA, Marcantonio-Junior E, da Silva VHP, Renno ACM. Biocompatibility of a porous alumina ceramic scaffold coated with hydroxyapatite and bioglass. Journal of Biomedical Materials Research - Part A. 2014; 102(7): 2072-2078.

[35] Peck MD. Epidemiology of burns throughout the world. Part I: Distribution and risk factors. Burns. 2011; 37(7): 1087-1100.

[36] Pourali P, Yahyaei B. The healing property of a bioactive wound dressing prepared by the combination of bacterial cellulose (BC) and Zingiber officinale root aqueous extract in rats. 3 Biotech. 2019; 9(2): 59.

[37] Pourali P, Yahyaei B. Biological production of silver nanoparticles by soil isolated bacteria and preliminary study of their cytotoxicity and cutaneous wound healing efficiency in rat. Journal of Trace Elements in Medicine and Biology. 2016; 34: 22-31.

[38] Pilehvar-Soltanahmadi Y, Dadashpour M, Mohajeri A, Fattahi A, Sheervalilou R, Zarghami N. An Overview on Application of Natural Substances Incorporated with Electrospun Nanofibrous Scaffolds to Development of Innovative Wound Dressings. Mini-Reviews in Medicinal Chemistry. 2017; 18(5): 414-427. 
[39] Klemm D, Heublein B, Fink HP, Bohn A. Cellulose: Fascinating biopolymer and sustainable raw material. Angewandte Chemie - International Edition. 2005; 44(22): 3358-3393.

[40] Kruse CR, Singh M, Targosinski S, Sinha I, Sørensen JA, Eriksson E, Nuutila K. (2017). The effect of pH on cell viability, cell migration, cell proliferation, wound closure, and wound reepithelialization: In vitro and in vivo study. Wound Repair and Regeneration. 2017; 25(2): 260-269.

[41] Proksch E. (2018). pH in nature, humans and skin. Journal of Dermatology. 2018; 45(9): 1044-1052.

[42] Blaak J, Staib P. The Relation of pH and Skin Cleansing. Current Problems in Dermatology. 2018; 54: $132-142$.

[43] Barud H da S, de Araújo Júnior AM, Saska S, Mestieri LB, Campos JADB, de Freitas RM, Ferreira NU, Nascimento AP, Miguel FG, Vaz MMOLL, Barizon EA, Marquele-Oliveira F, Gaspar AMM, Ribeiro SJL, and Berretta AA. Antimicrobial Brazilian Propolis (EPP-AF) Containing Biocellulose Membranes as Promising Biomaterial for Skin Wound Healing. Evidence-Based Complementary and Alternative Medicine. 2013; 703024.

[44] Morais ES, Silva NHCS, Sintra TE, Santos SAO, Neves BM, Almeida IF, Costa PC, Correia-Sá I, Ventura SPM, Silvestre AJD, Freire MG, Freire CSR. Anti-inflammatory and antioxidant nanostructured cellulose membranes loaded with phenolic-based ionic liquids for cutaneous application. Carbohydrate Polymers. 2019; 206: 187-197.

[45] Saska S, Scarel-Caminaga RM, Teixeira LN, Franchi LP, Santos RA Dos, Gaspar AMM, de Oliveira PT, Rosa AL, Takahashi CS, Messaddeq Y, Ribeiro SJL, Marchetto R. Characterization and in vitro evaluation of bacterial cellulose membranes functionalized with osteogenic growth peptide for bone tissue engineering. Journal of Materials Science: Materials in Medicine. 2012; 23(9): 2253-2266.

[46] Sanchavanakit N, Sangrungraungroj W, Kaomongkolgit R, Banaprasert T, Pavasant P, Phisalaphong M. Growth of human keratinocytes and fibroblasts on bacterial cellulose film. Biotechnology Progress. 2006; 22(4): 11941199.

[47] Lazarini SC, de Aquino R, Amaral AC, Corbi FCA, Corbi PP, Barud HS, Lustri WR. Characterization of bilayer bacterial cellulose membranes with different fiber densities: a promising system for controlled release of the antibiotic ceftriaxone. Cellulose. 2016; 23: 737-748.

[48] Karu TI. Cellular and molecular mechanisms of photobiomodulation (low-power laser therapy). IEEE Journal on Selected Topics in Quantum Electronics. 2014; 20(2): 7000306-7000306.

[49] Marquele-Oliveira F, da Silva Barud H, Torres EC, Machado RTA, Caetano GF, Leite MN, Frade MAC, Ribeiro SJL and Berretta AA. Development, characterization and pre-clinical trials of an innovative wound healing dressing based on propolis (EPP-AFß)-containing self-microemulsifying formulation incorporated in biocellulose membranes. International Journal of Biological Macromolecules. 2019; 136: 570-578.

[50] Song YH, Zhu YT, Ding J, Zhou FY, Xue JX, Jung JH, et al. Distribution of fibroblast growth factors and their roles in skin fibroblast cell migration. Molecular Medicine Reports. 2016; 14: 3336-42.

[51] Solmaz H, Ulgen Y, Gulsoy M. Photobiomodulation of wound healing via visible and infrared laser irradiation. Lasers in Medical Science. 2017; 32(4): 903-910.

[52] Reinke JM, Sorg H. Wound repair and regeneration. European Surgical Research. 2012; 49(1): 35-43.

[53] Hawkins DH, Abrahamse $H$. The role of laser fluence in cell viability, proliferation, and membrane integrity of wounded human skin fibroblasts following Helium-Neon laser irradiation. Lasers in Surgery and Medicine. 2006; 38(1): 74-83. 